\title{
Aproximaciones historiográficas al emperador Constantino en España durante el franquismo*
}

Esteban Moreno Resano

Universidad de Zaragoza

estmores@unizar.es

Fecha recepción 14.10.2017 / Fecha aceptación 25.01.2018

\section{Resumen}

Como todo sistema de gobierno de sesgo totalitario, el franquismo recurrió a la historia para justificar su existencia y forma. El emperador Constantino fue uno de los personajes a los que prestó atención, por su doble condición de príncipe victorioso en la guerra y varón piadoso. La imagen de Constantino evolucionó con la sucesión de las llamadas familias del régimen. Así, Eduardo Aunós trazó una semblanza del emperador acorde con los ideales del falangismo en 1940. El auge del nacionalcatolicismo propició la elaboración de nuevos retratos de Constantino. Dentro de este movimiento, el trabajo más comprometido con la ideología

\begin{abstract}
As with all movements leaning toward totalitarianism, Francoism too relied on history to justify its existence and form, focusing attention on, inter alia, Constantine the Great, given his double condition of victorious prince at war and pious man. Constantine's image evolved with the succession of the so-called 'families' of the Franco regime. Thus, Eduardo Aunós sketched the emperor's outline according to the ideals of Falangism in 1940. The growth of National-Catholicism further favoured the elaboration of new images of Constantine, and the most committed work under this movement was by Ramón Sara-
\end{abstract}

\footnotetext{
* Este artículo ha sido realizado gracias a la participación de su autor en el grupo de trabajo del proyecto de investigación HAR2016-77003-P, financiado por el Ministerio de Economía y Competitividad, y en el Grupo Hiberus, financiado por el Gobierno de Aragón.
} 
Miscelánea | Aproximaciones historiográficas al emperador Constantino en España durante el franquismo

oficial fue el publicado por Ramón Sarabia en 1951. Finalmente, la llegada de la tecnocracia propició la realización de estudios puramente académicos, como Censura en el mundo antiguo, de Luis Gil Fernández, de 1960.

\section{Palabras clave}

Constantino, España, franquismo, historiografía. bia (1951). Finally, with the arrival of technocracy, purely academic studies assumed the mantle, such as Luis Gil Fernández's Censure in the Ancient World (1960).

\section{Keywords}

Constantine, Spain, Franquism, historiography. 
EL RECURSO A LA HISTORIA CON FINES JUSTIFICATIVOS es un rasgo común de todos los regímenes de sesgo totalitario que surgieron en Europa en el segundo cuarto del siglo XX. Uno de los casos que se pueden recordar es la práctica identificación entre Mussolini y Constantino que se llevó a efecto en la Italia fascista, tal y como han analizado Canfora, Braccesi, Giardina, Guasco, Roda y Marcone ${ }^{1}$. Hasta ahora, sin embargo, no se ha dedicado ningún estudio a los acercamientos a la figura de este emperador que se realizaron en España durante el período franquista.

Ciertamente, el principado de Constantino no fue uno de los temas centrales de la historiografía española en aquella época. Constantino no había sido, como Trajano o Teodosio, un emperador «español $»^{2}$. Por otra parte, tampoco la cuestión constantiniana había sido desarrollada previamente en los medios académicos nacionales. Además, el régimen, después de apartar de la enseñanza a buena parte del profesorado universitario por razones políticas, fomentó, al menos, hasta 1965, los trabajos de carácter local frente a los que exigían horizontes geográficos distintos de la Península Ibérica. En efecto, a lo largo de la posguerra, el franquismo eliminó todo vínculo de las universidades españolas con su propia trayectoria académica y con

1. L. Canfora, Ideologie del classicismo, $1^{\text {a }}$ ed., Torino, 1980 (cito la traducción castellana de Ma M. Llinares García: Ideologías de los estudios clásicos, Madrid, 1991), 74; L. Braccesi, "Costantino e i Patti Lateranensi”, Studi Storici, 32, 1991, 161-167 (=G. Bonamente y F. Fusco, eds., Costantino il Grande dall'Antichità all'Umanesimo, $1^{\text {a }}$ ed., Macerata, 1993, vol. I, 203-211; A. Giardina y A. Vauchez, Il mito di Roma. Da Carlo Magno a Mussolini, $1^{\text {a }}$ ed., Roma, 2000, 254-258; A. Guasco, "Il nuovo Costantino fascista. Immagini e utilizzi dell'imperatore tra Chiesa e regime", en Costantino I. Enciclopedia Costantiniana sulla figura e l'immagine dell'imperatore del considetto Editto di Milano (313-2013), $1^{\text {a }}$ ed., Roma, 2013, vol. III, 469480; S. Roda, "Augusto e Costantino o dell'uso político degli anniversari”, en Atti dell Convegno di Studio Colloquium Augusteum. Il "perfetto inganno": Augusto e la sua politica nel bimilenario de la morte, $1^{\text {a }}$ ed., Torino, 2014, 39-67; A. Marcone, "Costantino nella storiografia italiana tra le due guerre mondiali", en L. De Salvo, E. Caliri y M. Casella, eds., Fra Costantino e i vandali. Atti del Convegno di Studi per Enzo Aiello (1957-2013) (Messina, 29-30 ottobre 2014), 1ª ed., Bari, 2016, 297-305.

2. A. Prieto Arciniega, "El franquismo y la historia antigua", en II Jornades L'Autonoma i la innovaciò docent. 1 i 2 de juny de 1994, 1ª ed., Barcelona, 1995, 44-50, esp. 47; F. Wulff, Las esencias patrias. Historiografía e historia antigua en la construcción de la identidad española, 1a ed., Barcelona, 2003, 233; F. Pina Polo, "El estudio de la historia antigua en España bajo el franquismo", Anales de Historia Antigua, Medieval y Moderna, 41, 2009, 1-10. 
el exterior, con el fin de crear unos centros de enseñanza superior afines al régimen ${ }^{3}$. Este hecho explica el desinterés de los historiadores españoles de la época, pertenecieran o no al ámbito universitario, por la Historia Antigua universal en cualquiera de sus etapas.

Con relación a la figura histórica del emperador Constantino, aunque extensible a cualquier otro ámbito de la historia, cabe señalar que las características comunes de toda la investigación histórica en España en aquellos años (al menos, hasta la década de los Sesenta) fueron la clausura ante las corrientes vigentes en las escuelas de investigación extranjeras, la falta de medios (principalmente bibliográficos), el constante acecho de la censura y el escaso aliento desde las instancias de gobierno de toda investigación de carácter académico. No obstante, los autores afines al régimen (Antonio Tovar, Eduardo Aunós, Hilario Yaben y Ramón Sarabia), al igual que otros que no lo fueron, como Sanz de Andino y Luis Gil, dedicaron a la «cuestión constantiniana» algunas páginas que en la actualidad merecen un análisis, en términos ideológicos y conceptuales, pero también porque, de modo muy particular, intervinieron, de acuerdo con sus posibilidades y medios, en el debate acerca del legado político de Constantino y de la naturaleza y fines de su «conversión» al cristianismo.

Salvando la obra de Luis Gil, la mayor parte de estos trabajos están hoy olvidados. Ciertamente, pesa sobre ellos el estigma de haber ignorado las formas académicas y las corrientes de investigación que se desarrollaban en Europa. No obstante, algunos textos, como los de Gil y Suárez, defendían tesis metodológicamente fundamentadas. Gil lamentaba esta situación en el prólogo a la tercera edición de Censura en el mundo antiguo en estos términos:

Me entristece profundamente y me irrita por su injusticia cierta tendencia de la gauche divine actual a menospreciar, desde el punto de vista científico y cultural, los años que duró el franquismo, como si en ese período (...) no hubiera habido en España, aunque fuera a contracorriente, poetas excelsos, dramaturgos excelentes, buenos narradores, hilarantes humoristas, profesores, filósofos y científicos bien impuestos en sus materias, y no se hubiese desarrollado el tejido universitario del país a niveles muy superiores a la preguerra ${ }^{4}$.

Luis Gil denunciaba así el escaso reconocimiento en el medio académico español contemporáneo de la labor de un cierto número de profesionales que trataron de desarrollar los estudios humanísticos condicionados por la escasez de recursos materiales del país y el nulo apoyo administrativo. El propio autor reconoce ambos hechos un poco más adelante: «La penuria de la época invitaba a buscar en las bibliotecas europeas el aparato bibliográfico aquí inexistente». Por lo que refiere a la historiografía académica, Gil recuerda también que las especiales circunstancias políticas de España sugerían temas de investigación en otros ámbitos impensables y que además, obligaban a adoptar una expresión del saber científico «con formas indirectas y diversos grados de ocultación» $»^{5}$. Su defensa de aquella generación

3. G. Pasamar Alzuría, Historiografía e ideología en la posguerra española: la ruptura de la tradición liberal, $1^{a}$ ed., Zaragoza, 1991; M. Á. Marín Gelabert, Los historiadores españoles en el franquismo, 1948-1975. La historia local al servicio de la patria, $1^{\text {a }}$ ed., Zaragoza, 2005.

4. L. Gil Fernández, Censura en el mundo antiguo, $3^{\text {a }}$ ed., Madrid, 2007, 10-11.

5. L. Gil Fernández, Censura ..., op. cit., 11. 
de académicos es más encendida cuando aprecia que aquella universidad fue el germen de la actual universidad española y de su universal reconocimiento ${ }^{6}$.

Ciertamente, la historiografía española de los años centrales del siglo XX permaneció al margen de la forja y desarrollo de la llamada «cuestión constantiniana». Se trata ésta del debate historiográfico acerca de la persona y gobierno del emperador Constantino, pero, sobre todo, de la validez de las fuentes literarias sobre las que hasta el momento se había escrito la historia de Roma del siglo IV d. C. ${ }^{7}$ Y los ignoraban no por desconocimiento, sino por rechazar su metodología, profundamente crítica. Los estudios como Constantine the Great and the Christian Church (1930), de Norman H. Baynes, L'empereur Constantin (1932) o L'empire chrétien (1947), de André Piganiol, Constantin le Grand et le triomphe du christianisme (1938-1939), de Henri Grégoire, y The Conversion of Constantine and Pagan Rome (1948), de Andreas Alföldi, eran desconocidos en España. Todos estos títulos son herederos, en última instancia, de Die Zeit Konstantins der Großen (1853) del historiador de la cultura Jacob Burckhardt, Della fede storica di Eusebio di Cesarea nella Vita Constantini (1888), de Amedeo Crivelucci (1888), Geschichte der altchristlicher Literatur bis Eusebius (1893), del teólogo protestante liberal Adolf von Harnack, y Kaiser Constantin und die christliche Kirche (1913), de Eduard Schwartz.

No obstante, los términos de la quaestio Constantiniana sólo fueron rechazados expresamente desde los posicionamientos del falangismo y del nacionalcatolicismo, como hacen constar, respectivamente, Eduardo Aunós y Ramón Sarabia ${ }^{8}$. De hecho, la historiografía española de la época refleja nítidamente el sucesivo influjo de tres distintas familias franquistas: el falangismo, en los primeros años de la postguerra, el nacionalcatolicismo, entre finales de los Cuarenta y hasta mediados de los Cincuenta, y la tecnocracia, alentada por el ascenso de los ministros vinculados al Opus Dei, y que conllevó una limitada ruptura del aislamiento intelectual de España en los períodos previos. Así pues, la producción historiográfica española realizada durante el franquismo debe ser observada a la luz de la propia transformación del régimen para garantizar su pervivencia.

6. L. Gil Fernández, Censura ..., op. cit., 11.

7. Dada la complejidad de este debate, hasta el punto de constituir un singular apartado dentro de la historiografía contemporánea, se han realizado distintos trabajos con el fin de explicar cuál ha sido su evolución en los últimos años y servir así de guía para los investigadores de la misma. El estado de la cuestión constantiniana cuando escribieron Aunós y Sarabia ha sido analizado en los siguientes estudios: P. Petit, "L'état actuel de la question constantinienne 1939/1949”, Historia, 1, 1950, 82-96; F. Bajo Álvarez, "La quaestio Constantiniana”, Hispania Antiqua, 13, 1986-1989, 177-188.

8. E. Aunós Pérez, “Constantino el Grande, creador del Imperio”, Vértice. Suplemento literario, Diciembre 1940, 7; R. Sarabia, Constantino Magno, el primer caudillo cristiano, 1ª ed., Madrid, 1940, 340. 


\section{Los autores falangistas}

La primera referencia a Constantino en un texto de carácter ideológico en el régimen franquista se halla en una pequeña obra de Antonio Tovar titulada Imperio de España, publicada en Madrid en 1939 bajo los auspicios de Falange. El filólogo, entonces firme defensor de los principios del Movimiento, acusaba al emperador de «utilizar políticamente para el Imperio la fuerza de la Iglesia»". Para él, el Imperio romano había sucumbido ante el empuje del cristianismo y, como organización obsoleta que era, debía desaparecer para permitir la construcción de un nuevo orden político. Constantino, presentado como un manipulador, por tanto, no había hecho sino dilatar este proceso, fomentando la aparición de factores de disolución de la unidad institucional, situación que sólo podía ser calificada de caótica: «el esclavo se pone contra el señor, el campo contra la ciudad, el pagano contra el cristiano, el hereje contra el ortodoxo, Bizancio contra Roma, la Iglesia contra el Imperio» ${ }^{10}$.

La segunda se encuentra en el artículo "Constantino el Grande, creador del Imperio», que fue publicado en 1940 por el prolífico escritor Eduardo Aunós como un suplemento literario de la revista falangista Vértice. Aunós, abogado especializado en Derecho internacional y doctor en Derecho, había sido ministro de Miguel Primo de Rivera y diplomático y ministro con Franco ${ }^{11}$. El texto es, ante todo, ensayístico, aunque tiene cierta ambición historiográfica, dado que cita algunas fuentes antiguas, concretamente, la Vita Constantini de Eusebio de Cesarea y De caeremoniis de Constantino Porfirogéneta. Se trata de un escrito de carácter triunfalista, redactado un año después del fin de la Guerra Civil, que refleja la admiración de su autor por la cultura bizantina. Los paralelismos entre el Estado resultante de la contienda española y el Imperio constantiniano no son textuales, pero el relato de las sucesivas victorias del emperador contra sus adversarios alude inequívocamente a la historia española inmediata. De algún modo, Aunós dejaba a los lectores el campo abierto para que hicieran sus propias reflexiones e identificaran a Francisco Franco como un nuevo soberano restaurador de la unidad de un Imperio dividido. De acuerdo con su ánimo propagandístico, Aunós recordaba que las victorias de Constantino se debieron, al mismo tiempo, a la intervención divina y al esfuerzo humano ${ }^{12}$. Además, destacaba que el éxito del modelo político constantiniano obedecía a la combinación de la unidad político-administrativa y religiosa. Aunós lo expresaba con las siguientes palabras: «Iglesia universal, Imperio universal: unidad sobre la dispersión de los pueblos; unidad sobre las querellas de los hombres; Iglesia una, Imperio uno». El polígrafo proseguía señalando que el Imperio constantiniano «fue un imperio

9. A. Tovar Llorente, Imperio de España, $1^{\text {a }}$ ed., Madrid, 1939, 21. Sobre Tovar, véase: I. Peiró Martín y G. Pasamar Alzuria, "Antonio Tovar Llorente”, en Diccionario Akal de historiadores españoles contemporáneos, $1^{\text {a }}$ ed., Madrid, 2002, 631-634.

10. A. Tovar Llorente, Imperio ..., op. cit., 22.

11. I. Peiró Martín y G. Pasamar Alzuria, "Eduardo Aunós Pérez”, en Diccionario ..., op. cit., 93-94.

12. E. Aunós Pérez, "Constantino ..., op. cit., 7-8: «Estimamos que en la decisión de Constantino, como ocurre en todos los grandes acontecimientos históricos, convergen dos factores: el providencial y el humano». 
de honda espiritualidad y de armonías (...) entre la cruz y el haz lictor» ${ }^{13}$. El guiño al fascismo italiano es evidente. De acuerdo con su opinión, era necesaria la alianza entre la Iglesia y el Estado contemporáneo para garantizar la estabilidad política. Tanto la Iglesia como el Estado, cada uno con su respectiva estructura piramidal, no podían tener cesuras internas. A propósito del poder civil, Aunós recuerda que éste derivaba del religioso, siendo, en consecuencia, absoluto:

El emperador es el mensajero de Dios, y el pueblo, el sujeto pasivo que recibe todos los beneficios de esa correspondencia. (...). El emperador, como representante del poder angélico, no es tan sólo legislador y guerrero, sino además, juez. (...). En el Imperio todo depende de él; ninguna función administrativa escapa a su jurisdicción ${ }^{14}$.

Aunós se sirvió de una idealización del Imperio bizantino para justificar el nuevo modelo de Estado español sobre principios totalitarios. "Constantino el Grande, creador del Imperio» es, como se ha podido comprobar, una recapitulación sumaria de reflexiones históricas y políticas del autor, que ya había expuesto con mayor desarrollo en una biografía monográfica de Justiniano, Justiniano el Grande, emperador del mundo, publicada en el mismo año 1940, y que reelaboró en otra obra dedicada al Imperio romano de Oriente: Bizancio: viaje a un mundo desaparecido, de 1953.

\section{Los autores tradicionalistas y nacional-católicos}

La victoria de las potencias aliadas frente al Eje en 1945 creó un nuevo equilibrio internacional. El gobierno español, aun habiéndose declarado neutral en la contienda, había colaborado con la Alemania nazi y la Italia fascista, principalmente por afinidad ideológica, pero también por la deuda contraída con ambos países totalitarios a raíz de la ayuda que procuraron a Franco durante la Guerra Civil. La necesidad de desmarcarse de los regímenes derrotados al término de la Segunda Guerra Mundial propició algunos cambios en los discursos políticos oficiales, que buscaron identificarse con la defensa del tradicionalismo católico (que el régimen pretendía liderar frente a las democracias europeas) y todo aquello que se asociara a la lucha contra el comunismo, en tanto que se formaban los dos grandes bloques europeos de la Guerra Fría. Así mismo, los ensayistas históricos también trataron de desvincularse de la ideología franquista, sin enfrentarse directamente con los postulados oficiales. La excepción, en este caso, es la obra de Ramón Sarabia, Constantino, el primer caudillo cristiano, fruto del entusiasmo franquista de su autor.

Un ejemplo singular de los cambios en la orientación de las imágenes literarias de Constantino en los primeros años de la Guerra Fría es un singular texto, que no se puede considerar, como tal, historiográfico, debido al aristócrata Francisco Javier Sanz de Andino,

13. E. Aunós Pérez, "Constantino ..., op. cit., 13.

14. E. Aunós Pérez, "Constantino ..., op. cit., 14. 
y cuyo título es La orden de Constantino en Grande y de la Real Corona de Vandalia ${ }^{15}$. Con el mismo, su autor trata de demostrar los orígenes constantinianos de la orden de caballería a la que pertenecía, y que fija en la víspera de la misma batalla de Puente Milvio ${ }^{16}$. Sanz de Andino aprovechó para elaborar una semblanza hagiográfica de Constantino, que concluye en estos términos:

La historia le llama el Grande, pues no fue solamente un gran general y un gran hombre de Estado e igual casi a todos los grandes Apóstoles del cristianismo, sino que también fue un gran ciudadano y un hijo modelo lleno de ternura hacia su madre. La Iglesia de Oriente le cuenta entre sus santos ${ }^{17}$.

Constantino es presentado así como un modelo para todos los católicos:

(...) toda vez que sobre el universo ha caído nuevamente otra época de tinieblas, y cuando de día en día las circunstancias por que atraviesa el mundo, de sobras conocidas por todos, ponen de manifiesto, (...) el enorme papel que otra vez en el transcurso del tiempo corresponde al cristianismo, eternamente juvenil, en medio de la oscuridad y la congoja, única fuerza soberana en el mundo ${ }^{18}$.

A propósito de lo cual, Sanz apunta que, en la nueva situación mundial creada después de 1945, correspondía a la aristocracia organizada en la Orden Constantiniana liderar la renovación espiritual, moral y culturar de Europa y América tomando como modelo al emperador romano, la cual

(...) acoge bajo sus gloriosas insignias los eternos valores del cristianismo y del proceder caballeresco -hoy, por desgracia, olvidado entre los hombres-, así como de la cultura y verdadera civilización de la Europa eterna $(\ldots)^{19}$.

Sanz de Andino no muestra adhesión al ideario oficial del régimen en ninguna de sus expresiones, pero su defensa de los valores tradicionales de corte medieval era acorde con las aspiraciones nobiliarias del dictador, concretadas en el matrimonio de su hija con el Marqués de Villaverde en 1950.

15. Madrid, 1947.

16. F. J. Sanz de Andino, La Orden de Constantino en Grande y de la Real Corona de Vandalia, $1^{\mathrm{a}}$ ed., Madrid, 1947, 27-33. Actualmente, la Orden Constantiniana reconoce que su constitución data del año 1190, y considera un hecho legendario remontar su origen a la víspera de la batalla de Puente Milvio. Cf. Gr. Gatscher-Riedl, In hoc signo vinces. Die Geschichte des Heiligen Konstantinischer Ritterordens vom Heiligen Georg. Zwischen religiösem Mythos und politischem Anspruch von Byzanz nach Neapel, 1ª ed., Wien, 2012.

17. F. J. Sanz de Andino, La Orden ..., op. cit., 33.

18. F. J. Sanz de Andino, La Orden ..., op. cit., 15.

19. F. J. Sanz de Andino, La Orden ..., op. cit., 16. 
No obstante, más representativa de la época es la biografía Osio, obispo de Córdoba, del canónigo seguntino Hilario Yaben y Yaben ${ }^{20}$. Con esta obra, Yaben desarrolló un capítulo de la segunda parte del tomo primero de la Historia Eclesiástica de España de García Villada, dedicado específicamente a la figura de Osio. Aunque conserva los rasgos formales de un trabajo académico, el estudio de Yaben, según declara su autor, es un texto hagiográfico, pues su principal propósito era postular la elevación del obispo hispano a los altares y su reconocimiento como Doctor de la Iglesia, haciéndolo así constar en la conclusión:

Loor inmortal al gran obispo, del cual se valió la providencia para escribir el símbolo de la fe y combatir eficazmente errores y divisiones. (...) ¡Ojalá podamos honrarlo pronto como a Padre y Doctor de la Iglesia! ${ }^{21}$.

No se trata, como se puede apreciar, de un trabajo realizado con ánimo de hacer apología del régimen franquista, sino de un texto de historia eclesiástica. A pesar de ello, y aunque la biografía de Osio no contenga manifiestos políticos, debe ser relacionada con el inicio del encumbramiento del nacionalcatolicismo dentro de la sucesión de familias en el gobierno español de la época. El intento de propugnar la canonización de un nuevo santo español, y más como doctor de la Iglesia, junto a Leandro e Isidoro de Sevilla, Eugenio e Ildefonso de Toledo, Juan de la Cruz y Teresa de Jesús, vendría a confirmar la idea de que España siempre había sido y seguiría siendo un bastión de la ortodoxia religiosa.

Yaben, al tratar la figura de Osio, tenía que analizar necesariamente la de Constantino, pues fue instruido en la fe cristiana por el obispo hispano. El canónigo no adoptó el tono triunfalista que había empleado Aunós en el trazado del perfil histórico del emperador. Frente a la idealización del soberano en Aunós, y aun asumiendo que la victoria del emperador se debía a la intervención divina, Yaben comprendió el principado de Constantino como un período de decadencia política. Así se expresaba el canónigo a propósito de la conversión del emperador:

El Imperio iba a pasar de pagano a cristiano. Por desgracia, la paz entre la Iglesia y el Imperio llegaba demasiado tarde. El Imperio estaba ya decrépito y ni con la inyección de la savia vital del cristianismo podía recobrar su vigor. $(. . .)^{22}$.

Es más, Constantino era un emperador piadoso y bienintencionado, pero limitado en su actuación por las circunstancias de su tiempo, por lo que señala un poco más adelante:

Constantino, emperador de Occidente, pensó, desde luego, en acabar definitivamente con las persecuciones de la Iglesia y declarar perfectamente lícito el culto católico. Por el momento no se podía hacer más. No era posible condenar el paganismo ni dificultar su culto. No era posible siquiera declarar el cristianismo religión del Estado, porque todavía aún conservaba mucha

20. Barcelona, 1945. Cf. R. Sarabia, Constantino ..., op. cit., 122, 138-139.

21. H. Yaben y Yaben, Osio, obispo de Córdoba, 1a ed., Barcelona, 1945, 163 y 165.

22. H. Yaben y Yaben, Osio ..., op. cit., 37. 
fuerza la vieja. Constantino comprendió que, como emperador cristiano, debía limitarse, por el momento, a favorecer la nueva religión y a estimular las conversiones por el ejemplo y la persuasión, sin emplear en lo más mínimo la fuerza ${ }^{23}$.

Para Yaben, el principado de Constantino no fue un modelo de Estado, pues el propio Imperio romano era un sistema de gobierno caduco e insostenible. El emperador no podía actuar más allá de sus posibilidades. En cierto modo, esta valoración de la actuación política de Constantino supone un ejercicio de crítica histórica. En todo caso, ésta no la hacía con el fin de reconstruir el pasado, sino de ensalzar las virtudes de Osio y defender su santidad y su ortodoxia. Como hombre de Iglesia, Yaben escribe sobre la Iglesia y para la Iglesia, y, en particular, sobre la Iglesia española. El canónigo era afín al régimen, pero su compromiso con él era también limitado. Se había declarado partidario de la monarquía en 1931, pero, desde la proclamación de la Segunda República comenzó a adoptar posturas alejadas del liberalismo, llegando a afirmar que los partidos políticos eran funestos para el funcionamiento del país ${ }^{24}$. No obstante, firmó el manifiesto de los obispos españoles en apoyo a Franco redactado por el cardenal primado Isidro Gomá en $1937^{25}$. Sus personales explican por qué su semblanza de Constantino no se ajustaba plenamente al discurso oficial del régimen, aunque trabajos como el suyo eran bien recibidos en coincidencia con el auge del nacionalcatolicismo.

Más compleja es la biografía de Constantino publicada en 1951 por el sacerdote redentorista Ramón Sarabia, y que lleva por título Constantino Magno, el primer caudillo cristiano. Además de ser un texto apologético del providencialismo histórico, se trata de una biografía encomiástica del emperador, cuyo propósito es presentarle como modelo de conducta ${ }^{26}$. El autor exhorta a sus lectores a ponderar su carácter, su valor y su generosidad, a que les sirva de modelo y a imitarle ${ }^{27}$. En este sentido, a título de rey y guerrero piadoso, le equipara a Fernando III de Castilla, y como estratega y estadista, a Napoleón ${ }^{28}$. De todos modos, su intencionalidad política es manifiesta, ya que fue dedicada «al caudillo Franco»:

Así os llamó el pueblo español en las horas trágicas, cuando os alzasteis en los campos africanos (...) para salvar a nuestra España de las garras del comunismo. (...). Caudillo sois de nuestra patria, y la voz misteriosa que se alza en el corazón de la historia contemporánea nos está diciendo que seréis caudillo y salvador de aquellas ideas cristianas que son las únicas que nos pueden salvar. (...).

23. H. Yaben y Yaben, Osio ..., op. cit., 39.

24. H. Yaben y Yaben, «Gobiernos de partidos y gobiernos de capacidades», Revista Eclesiástica, 1931, 113. Cf. W. J. Callahan, The Catholic Church in Spain, 1875-1998, 1ª ed., Washington, 2000, 223-224, 558, n. 10 (cito la traducción española, Barcelona, 2002).

25. I. Gomá y Tomás, «Carta colectiva del episcopado español», en Por Dios y por España. Pastoralesinstrucciones pastorales y artículos-discursos-mensajes-apéndice 1936-1939, 1ª ed., Barcelona, 1940, 590.

26. R. Sarabia, Constantino ..., op. cit., 26.

27. R. Sarabia, Constantino ..., op. cit., 7.

28. R. Sarabia, Constantino ..., op. cit., 273 y 287. 
Concluye la dedicatoria Sarabia profetizando que «todo el mundo saludará la estatua de Franco, caudillo de la Cruzada mundial contemporánea» ${ }^{29}$. No es la única comparación inequívoca entre el Imperio de comienzos del siglo IV y la España del segundo tercio del XX. En efecto, a mitad del libro afirma:

(...) para entender las discordias fatales del siglo IV (...) quizás nos convenga tener delante sucesos de hoy que hemos visto con nuestros propios ojos y cuya realidad hemos palpado con honda emoción. Sentóse en el trono de la monarquía española la república laica y atea. (...) Tenía que erguirse el alma española saturada de indignación. Y se irguió. Estalló la guerra contra el comunismo, que se había calado el gorro frigio y se había aliado con la soviética Rusia ${ }^{30}$.

Tal y como se deduce del prólogo, la obra de Sarabia tampoco es un trabajo académico, aunque esto no le impida, al igual que Aunós, rechazar sin mayores argumentos las tesis defendidas por los historiadores liberales decimonónicos Duruy y Burckhardt ${ }^{31}$. Como se puede observar, Sarabia desconocía el artículo de Aunós. Es posible que rechazara su afecto por el cismático Imperio bizantino. De hecho, a diferencia de Aunós, que sólo cita autores griegos, Sarabia, además de reproducir traducciones de Eusebio de Cesarea, Metodio de Olimpia y Juan Crisóstomo, recoge pasajes de escritores latinos como Lactancio, Amiano Marcelino, Aurelio Prudencio y el Liber pontificalis ${ }^{32}$. Frente a la fascinación por el oriente griego de Aunós, Sarabia acentúa los rasgos occidentales y latinos del Imperio constantiniano. Además, el ideario nacional-católico es mucho más evidente, sobre todo, en la asociación del centralismo de lo hispano en el mundo romano con el catolicismo riguroso. Sin embargo, en algo coinciden Aunós y Sarabia al comparar a Franco con Constantino: siendo éste un personaje de la Historia universal, el franquismo también adquiría pretensiones universalistas. Desde su punto de vista, España era el origen de una nueva cruzada destinada a reconquistar Europa para el cristianismo.

En este tipo de trabajos afectos al régimen, la propaganda desplaza a la historia. La escasa calidad científica de estos trabajos explica su olvido más allá de los años inmediatos. De hecho, tuvieron una repercusión muy limitada en los círculos académicos, a pesar de ser los escasos trabajos sobre la materia de la época. La obra de Sarabia, sin embargo, aparece citada en una crónica bibliográfica de la revista Jerónimo Zurita de $1953^{33}$. Sarabia, de hecho, no era un académico. Según refiere en un texto de carácter autobiográfico, ¿España ... es católica?, se había formado en el seminario redentorista de Astorga, gracias a las lecturas de pensadores decimonónicos adversarios del liberalismo. Posteriormente, desde 1902 hasta 1950,

29. R. Sarabia, Constantino ..., op. cit., 5-6.

30. R. Sarabia, Constantino ..., op. cit., 123-124.

31. R. Sarabia, Constantino ..., op. cit., 340.

32. R. Sarabia, Constantino ..., op. cit., 23, 36, 73-74, 84-86, 111-112, 176, 283 (Eusebio de Cesarea); 109 (Metodio de Olimpia); 279 (Juan Crisóstomo); 41, 111-112, 203, 237 (Lactancio); 199 (Amiano); 43 (Prudencio); 264 (Liber pontificalis).

33. "Contribución historiográfica de la Institución Fernando el Católico”, Cuadernos de Historia Jerónimo Zurita, 4-5, 1953, 175-205. 
se dedicó a la predicación en las misiones rurales ${ }^{34}$. De acuerdo con su dedicación pastoral, los fines de su retrato de Constantino son más catequéticos que historiográficos. De acuerdo con sus propósitos, sometía el método a los propósitos de su trabajo. En aras del mismo, su falta de rigor crítico alcanza extremos que podrían ser calificados de ingenuos. En concreto, presenta a Hispania como centro del Imperio y a Madrid como cuna del papa Melquíades ${ }^{35}$. Con el mismo presupuesto historiográfico, rechaza todas las teorías concebidas dentro de la «cuestión constantiniana» simplemente porque no se ajustan a sus fuentes de conocimiento histórico, que no son tanto los textos de la época, cuanto una serie de manuales de historia universal y eclesiástica del siglo XIX, accesibles en las bibliotecas de seminarios y otros institutos religiosos, que debió de consultar durante su preparación para el sacerdocio en Astorga. Con la excepción de Les martyrs (1804) de Chateaubriand (1768-1848), todos ellos eran de tendencias historicistas ${ }^{36}$. Por supuesto, todos los autores que cita son católicos. Además de Chateaubriand, cabe recordar, entre los autores decimonónicos citados por Sarabia, al académico bávaro-austríaco Johann Baptist von Weiss (1820-1899), autor de una Weltgeschichte, traducida al castellano en 1927, y a los franceses René François Rohrbacher (1789-1856), que publicó una Histoire de l'Église en 1842, Fréderic Ozanam (1813-1853), autor de La civilisation au Ve. siècle (1856), Jacques Victor de Broglie (1821-1901), autor de L'Église et l'Empire romain au IV siècle (1856), y Fernand Mourret (1854-1938), autor de una Histoire générale de l'Église, publicada en castellano en $1918^{37}$.

Sarabia cita también historiadores eclesiásticos españoles de la primera mitad del siglo $\mathrm{XX}$, cuyo manejo imprime a su trabajo un particular sello nacionalista desde el más ortodoxo catolicismo. Estos autores españoles son el jesuita Zacarías García Villada e Hilario Yaben. Sarabia cita con frecuencia la ya comentada biografía de Osio de Yaben ${ }^{38}$. García Villada, víctima de la Guerra Civil, había publicado la Historia eclesiástica de España, que apareció en sucesivas partes entre 1929 y 1936. Además, había dado a la imprenta en el mismo año 1936 El destino de España en la Historia universal, ensayo de cuño nacional-católico, reeditado en 1940, que aparece reflejado en la obra de Sarabia ${ }^{39}$. Conviene hacer una precisión a las concepciones políticas que se aprecian la obra de García Villada. García Villada evolucionó con su época. En la primera parte de la Historia eclesiástica de España, publicada en 1929, aboga por la separación entre el poder civil y el eclesiástico como principio de gobierno, adscribiéndose así a un liberalismo moderado, como demuestra su comentario a la carta del obispo Osio de Córdoba a Constancio $\mathrm{II}^{40}$. Su deriva hacia el nacionalcatolicismo se produjo en los

34. W. J. Callahan, The Catholic Church ..., op. cit., 179, 193-195.

35. R. Sarabia, Constantino ..., op. cit., 12 y 182. Duruy pertenecía a los círculos liberales de Renan. Era autor de Histoire romaine (Paris, 1847).

36. R. Sarabia, Constantino ..., op. cit., 93, 193.

37. R. Sarabia, Constantino ..., op. cit., 34 (Weiss), 83 (Mourret), 129 (De Broglie), 185 (Ozanam), 265 (Rohrbacher).

38. R. Sarabia, Constantino ..., op. cit., 122, 138-139.

39. R. Sarabia, Constantino ..., op. cit., 41, 122.

40. Athan. Alex., Apol. contr. Arr., XXV, 58. Cf. Z. García Villada, Historia Eclesiástica de España, I, 2a parte, $1^{\text {a }}$ ed., Madrid, 1929, 34. 
años treinta, en el contexto de la política laicista de la Segunda República ${ }^{41}$. Sarabia, como es lógico, se adhirió a la última corriente política abrazada por García Villada.

Uno de los aspectos más destacables, desde el punto de vista conceptual, al que prestaron atención los autores adscritos al nacional-catolicismo es la relación entre los poderes públicos y la religión, y, más en concreto, la forma y la confesionalidad del Estado. Además de los comentarios referidos a este particular debidos a Yaben y Sarabia, conviene recordar los pasajes que el canonista costarricense José Salazar Arias, que, después de doctorarse en Roma, en la Pontificia Universidad Gregoriana, publicó en Madrid, en 1954, la obra Dogmas y cánones de la Iglesia en el Derecho romano (apuntes históricos). Salazar, conforme a criterios esencialmente jurisprudenciales, identifica a Constantino como un soberano absoluto, advirtiendo que los emperadores cristianos «debieron (sic) entender su absolutismo como lo debe entender un cristiano, es decir, subordinado a la ley divina y obligado a favorecer su observancia ${ }^{42}$. Para Salazar, el Imperio constantiniano representa el primer modelo de «Estado católico», frente a la opinión de Palanque, Biondi y Kurtscheid, que no advertían el carácter confesional cristiano del Imperio antes de la ley Cunctos populos de 380. Según el autor, durante el principado de Constantino, el Imperio romano había adquirido la condición de Estado católico, aunque no de modo definitivo ${ }^{43}$. Ahora bien, en el Estado católico, la religión no estaba al servicio del poder público, sino que éste servía a la religión. Y, a su juicio, esta situación se dio en época de Constantino, que impuso el culto cristiano y la obediencia a los cánones de la Iglesia ${ }^{44}$.

Ciertamente, Salazar no fue un ideólogo del franquismo, pero su forma de comprender las relaciones entre el poder público y la religión se ajustaban a la imagen que el régimen franquista quería proyectar de sí mismo en el período de predominio de la familia nacionalcatólica en los gabinetes ministeriales españoles: el Estado estaba subordinado a la Iglesia católica y, como tal, promovía el culto romano y restringía las posibilidades de que se desarrollara la práctica de ninguna otra religión.

\section{La tecnocracia}

El desarrollo económico y la limitada apertura intelectual respecto a los medios académicos extranjeros impulsados desde finales de los cincuenta y hasta el final del régimen por la tecnocracia favorecieron la elaboración de otro tipo de obras historiográficas. Pero la promoción

41. I. Peiró Martín y G. Pasamar Alzuria, “Zacarías García Villada”, en Diccionario ..., op. cit., 285-286.

42. J. V. Salazar Arias, Dogmas y cánones de la Iglesia en el Derecho romano (apuntes históricos), $1^{\text {a }}$ ed., Madrid, 1954, 52.

43. G. R. Palanque, Histoire de l'Église depuis les origines jusq'à nous jours, III. De la paix constantinienne à la mort de Théodose, $1^{\text {a }}$ ed., Paris, 1936; B. Biondi, "L'influenza di Sant'Ambrogio sulla legislazione religiosa del suo tempo", en Sant'Ambrogio nel XVI centenario della nascita, $1^{a}$ ed., Milano, 1940, 372-374; B. Kurtscheid, Historia iuris canonici. Historia institutorum, I, 1ª ed., Roma, 1941, 99. Cf. J. V. Salazar Arias, Dogmas ..., op. cit., 144-145.

44. J. V. Salazar Arias, Dogmas ..., op. cit., 206-207. 
de la investigación académica no debe juzgarse como un intento de superación del pasado político, sino, todo lo contrario, como una necesidad para su supervivencia. Así, el franquismo abrió la puerta a estudios humanísticos mejor trabados para su mayor gloria y justificación. Pero esta apertura conllevó ciertos riesgos. Como, por ejemplo, la publicación de Censura en el mundo antiguo. En sí, la monografía sobre la censura no tenía una motivación política expresa, es decir, no pretendía provocar ninguna reacción por parte del poder. Era un estudio científicamente riguroso, cuyo tema vino procurado por el particular medio político en el que realizó su carrera Luis Gil ${ }^{45}$. Así pues, a pesar de esta consideración, el trabajo, en palabras del autor, era una «crítica indirecta del sistema» ${ }^{46}$. La ideología del autor, hijo de un represaliado por el régimen y afín al republicanismo, se halla debidamente disimulada ${ }^{47}$. Según indica el prólogo a la primera edición, de 1960, la idea para redactar un libro sobre la censura en la Antigüedad nació de los cursos sobre crítica textual que había impartido en la Universidad de Madrid entre 1957 y $1959^{48}$. La intencionalidad última era, de todos modos, política: hacer un buen trabajo humanístico cuando no se podía hacerlo. Pero este hecho sólo lo descubrió en el prólogo a la segunda edición, realizada en 1984, cuando proclamó:

(...) era, fui y soy un liberal en el sentido clásico del término, es decir, una persona convencida de que todos los hombres tienen derecho a exponer su pensamiento y profesar libremente sus creencias $(\ldots)^{49}$.

El trabajo de Gil dedica tres capítulos a la represión de la alteridad ideológica durante el principado cristiano. El autor hace eco de la cuestión constantiniana, a la que tanto habían contribuido las distintas escuelas historiográficas europeas durante el primer y el segundo tercio del siglo XX. Lejos de los planteamientos de Aunós y Sarabia, que presentan a un Constantino idealizado, el Constantino de Gil es un «homo politicus», antes que un soberano piadoso, que ejerció la represión de cualquier modo de pensamiento que amenazara su autoridad. Así dice el autor:

Los emperadores cristianos, el primero de ellos Constantino, recibieron la herencia de sus antecesores inmediatos ilirio-pannonios del siglo III, que, a punta de lanza y filo de espada, con una política de robustecimiento progresivo de la autocracia, lograron apuntalar el edificio en ruinas de un Imperio al que las presiones fronterizas de los bárbaros, los conflictos religiosos, las incipientes diferenciaciones nacionales y la enorme crisis económica estaban a punto de derruir hasta sus cimientos ${ }^{50}$.

45. L. Gil Fernández, Censura ..., op. cit., 21.

46. L. Gil Fernández, Censura ..., op. cit., 20.

47. I. Peiró Martín y G. Pasamar Alzuría, "Luis Gil Fernández», en Diccionario ..., op. cit., 296-297.

48. L. Gil Fernández, Censura ..., op. cit., 23.

49. L. Gil Fernández, Censura ..., op. cit., 17.

50. L. Gil Fernández, Censura ..., op. cit., 318. 
Un poco más adelante, Gil confirma su aceptación de la cuestión constantiniana, señalando que el emperador, lejos de ser un soberano dechado de todo tipo de virtudes morales y políticas, era «un hombre de otras épocas, y se imponía en él el talento político a las convicciones religiosas $»^{51}$. Cada una de sus opiniones aparece refrendada por el erudito ejercicio de la cita de fuentes y autores europeos de la época, referencias que fue ampliando en las dos ediciones posteriores de la obra. Entre ellos, quizá el más destacado, por su influjo en la historiografía de la época, es André Piganiol, que publicó en 1947 L'Empire chrétien, dentro de la Histoire romaine dirigida por Glotz ${ }^{52}$. También menciona otros trabajos clásicos de la historiografía del S. XX sobre la Antigüedad tardía, concretamente, Christianity and Classical Culture. A Study on Thought and Action from Augustus to Augustine (1940), de Charles N. Cochrane, y La persécution del christianisme dans l'Empire romain (1956), de J. Moreau ${ }^{53}$. El texto de Gil tiene giros irónicos que sólo se pueden comprender desde el particular ambiente intelectual de la España franquista, muy habituada a la expresión solapada de ciertas ideas. Por ejemplo, cuando comenta el Edicto de Tesalónica, que supuso la imposición del dogma niceno a todos los ciudadanos romanos, apostilla sobre Teodosio I: «nacido en España, por cierto» ${ }^{54}$. Se trata del tópico de la asociación de rigorismo doctrinal ortodoxo y origen nacional hispano, pero vuelto del revés. Téngase en cuenta que Teodosio, que recibía el apelativo de El Grande, ya había sido presentado como un icono nacional en Imperio de España de Antonio Tovar.

Pero este humor, así como, en general, las estrategias de expresión empleadas para evitar la censura no fueron comprendidos por los lectores de la obra de Gil en los medios académicos europeos. Lo comenta el propio autor en el segundo prólogo a la obra, donde rechaza tanto los elogios que le dirigió en su reseña Alexander Demant a título de defensor de la libertad de expresión en un medio hostil a la misma, como las críticas que recibió de Van Son como enemigo del liberalismo ${ }^{55}$. La obra, sin embargo, fue muy bien recibida -y entendidapor los investigadores españoles e hispanoamericanos, como demuestran, entre otros, los comentarios de Vázquez Zamora y Alsina, a juicio del propio Gil ${ }^{56}$.

La apertura a las escuelas académicas europeas y la identificación de Constantino como un príncipe reformador que, apoyándose en un modelo autoritario, consiguió preservar al Imperio en un período de inestabilidad militar, al igual que el debate acerca de la naturaleza de su conversión están representados en otra obra historiográfica de este período, el manual de Historia de Roma publicado por Luis Suárez Fernández en Bilbao en 1967. Suárez era

51. L. Gil Fernández, Censura ..., op. cit., 346.

52. L. Gil Fernández, Censura ..., op. cit., 449, n. 2.

53. L. Gil Fernández, Censura ..., op. cit., 444, n. 13; 442, n. 57.

54. L. Gil Fernández, Censura ..., op. cit., 391.

55. L. Gil Fernández, Censura ..., op. cit., 19-21. Los comentarios aparecen en las reseñas aparecidas respectivamente en L'Antiquité Classique, 32, 1963, 724 y Mnemosyne, 15, 1962, 417-420.

56. Destino, 2 de diciembre de 1961; La Vanguardia Española, 24 de mayo de 1963. Añádase a éstos los de J. Díaz Tejera en Emérita (31, 1963, 321-322) y C. Láscaris (Revista de Filología de la Universidad de Costa Rica, 4, 1963, 115-116). Cf. L. Gil Fernández, Censura..., op. cit., 19. 
medievalista, pero su condición de Catedrático de Historia Antigua y Medieval de la Universidad de Valladolid entre 1955 y 1973 le llevó a preparar un libro de texto de historia romana con fines didácticos ${ }^{57}$.

Luis Suárez, muy comprometido con el régimen (pues fue Director General de Universidades e Investigación entre 1972 y 1974), destaca la faceta reformadora de Constantino en el ámbito administrativo, soslayando su política religiosa. En primer lugar, advierte de la esencial continuidad formal entre los principados de Diocleciano y Constantino:

Difícilmente podríamos separar a Diocleciano de Constantino cuando se trata de analizar su obra. Ésta consiste en un cierto número de reformas que condujeron a crear un nuevo régimen, etapa final en la tendencia al absolutismo demostrada desde la época de Septimio Severo: el dominado. (...) Casi todas estas reformas (...) venían dictadas por las necesidades y problemas que apenas consentían otra solución que la que se dio: sacrificar el bienestar de los habitantes del Imperio a la salvación de éste y la libertad a la unidad de mando. (...) El absolutismo, extremado más aún por Constantino, desarrolló la burocracia ${ }^{58}$.

Suárez insiste en que el «dominado» (término acuñado por Mommsen y asumido por los romanistas y, en general, por los historiadores del Derecho, en relación con el Imperio romano tardío), era «un nuevo régimen social, político y económico, profundamente original y muy duro, que habría de transmitirse a la Edad Media como uno de los ingredientes utilizados en la edificación de las monarquías» ${ }^{59}$.

La singular aportación de Luis Suárez al desarrollo de la cuestión constantiniana en la historiografía española, con relación a cuanto se había escrito en las dos etapas precedentes del período franquista, es la relativización de los aspectos religiosos de su política. Así lo afirma el medievalista, en referencia al fundamento divino de la autoridad imperial:

La conversión al Cristianismo no cambió mucho las cosas, pues los autores cristianos estuvieron conformes en reconocer que, viniendo de Dios el poder, el poder participa en cierto sentido de la naturaleza divina ${ }^{60}$.

Y acerca de las razones personales de su adopción del cristianismo como religión, también se mostraba un tanto escéptico:

Las opiniones de los historiadores varían: unos, como Ferdinand Lot o Palanque, admiten su sinceridad; otros, como Burckhardt, la niegan; otros, finalmente, como Piganiol y Salvatorelli,

57. I. Peiró Martín y G. Pasamar Alzuría, "Luis Suárez Fernández", en Diccionario ..., op. cit., 602-604.

58. L. Suárez Fernández, Panoramas de la Historia Universal. I. Historia de Roma, $1^{\text {a }}$ ed., Bilbao, 1967, 271-273.

59. L. Suárez Fernández, Panoramas ..., op. cit., 287.

60. L. Suárez Fernández, Panoramas ..., op. cit., 287. 
creen que en Constantino se produjo una evolución similar a la que experimentaba entonces la sociedad romana y que su cristianismo fue término de llegada de un monoteísmo sincrético ${ }^{61}$.

Como se puede observar, sin ser un especialista en la cuestión constantiniana, Suárez estaba relativamente bien informado acerca del debate sobre la naturaleza de la conversión del emperador. Fundamentalmente, además de la obra clásica de Burckchardt, había leído algunos textos de la escuela francesa (Lot, Palanque y Piganiol) y uno de la italiana (Salvatorelli). No menciona, sin embargo, ni los agresivos planteamientos del belga Grégoire ni las monografías sobre Constantino publicadas después del final de la Segunda Guerra Mundial por los alemanes Alföldi, Dörries y Kraft ${ }^{62}$.

Suárez, en general, ofrece una imagen decadente del principado de Constantino, desde el punto de vista económico y cultural:

La situación económica se hacía cada vez más difícil. El absolutismo oriental del dominado representó un aumento de los gastos. (...) Una nueva sociedad surgía entre tanto, estructurada en nuevos moldes culturales y económicos. Roma se iba muriendo al dar vida a la cristiandad. (...) El absolutismo y el cristianismo hacían triunfar el poder del número de una masa amorfa, (...). La cultura se deterioraba, la razón era suplantada por la fe y las medidas que trataron de tomar las autoridades fracasaban por la presión militar y por la escasez de mano de obra, que hacía más difícil la vida económica. Vulgaridad y barbarismo son las notas dominantes. (...) El mal gusto impera, imponiendo a la arquitectura las proporciones gigantescas de la basílica de Majencio o de la de Constantino. Roto el predominio de la razón, el arte se hacía expresionista. ${ }^{63}$

En un momento histórico en que se primaba el desarrollo técnico, económico y cultural, la asociación del principado de Constantino con el comienzo de la decadencia romana suponía hacer de este emperador todo lo contrario de un monarca modélico. Además, en la década de los años Sesenta, en el contexto de la Guerra Fría, el régimen franquista buscaba asimilarse a las democracias occidentales. Con ese fin, promovió la aprobación de la Ley Orgánica del Estado en 1967, que definía el sistema político español como «democracia orgánica» $^{64}$.

61. L. Suárez Fernández, Panoramas ..., op. cit., 283.

62. A. Alföldi, The Conversion of Constantine and the Pagan Rome, $1^{\text {a }}$ ed., Oxford, 1948; H. Dörries, Das Selbstzeugnis Kaiser Konstantins, $1^{\text {a }}$ ed., Göttingen, 1954; H. Kraft, Kaiser Konstantins religiöse Entwicklung, $1^{\text {a }}$ ed., Tübingen, 1955.

63. L. Suárez Fernández, Introducción ..., op. cit., 292-293.

64. Sobre la «democracia orgánica», veáse: M. A. Giménez Martínez, "La democracia orgánica: participación y representación política en la España de Franco", Espacio, Tiempo y Forma (Historia Contemporánea), 27, 2015, 107-130. 


\section{Consideraciones finales}

El emperador Constantino no fue uno de los personajes históricos en los que reparó el franquismo para su explotación propagandística, por lo que tampoco fomentó la realización de estudios sobre su vida y obra política. No obstante, a lo largo de los treinta y nueve años de permanencia de Franco como Jefe del Estado español, su figura fue revisada conforme las distintas familias políticas del régimen se sucedían en los gobiernos. Salvado el rechazo de la obra política del emperador el Imperio de España de Antonio Tovar, el falangismo, en la década de los Cuarenta, encontró en Constantino, de la mano de Eduardo Aunós, un soberano ejemplar, que representaba la necesidad de un poder único y autoritario, con el apoyo de la Iglesia católica, para preservar la unidad nacional de la España contemporánea. Los autores nacional-católicos vieron también en Constantino un modelo de gobernante en los años Cincuenta. Aunque aparentemente son textos escasamente académicos, Yaben, Sarabia y Salazar aprovecharon la caracterización histórica del emperador como favorecedor del clero y el culto católicos para analizar el concepto de «estado confesional», en el que el poder público se hallaba sometido, cuando menos, desde el punto de vista moral, a la autoridad religiosa. Como se puede comprobar, hay una diferencia importante en la percepción de las relaciones entre Estado e Iglesia entre los autores falangistas y los nacional-católicos: para los primeros, la religión estaba supeditada a la autoridad política y militar (Aunós indicaba que todo en el Imperio dependía del emperador, representante de Dios ante sus súbditos), en tanto que para los segundos, el poder político debía mostrar una relativa subordinación al espiritual. A partir de la década de los años Sesenta, el desarrollismo facilitó el estudio académico del principado de Constantino. Siendo Luis Gil y Luis Suárez investigadores de muy diferente adscripción metodológica (Gil era filólogo y Suárez medievalista) y política (el primero, hijo de republicanos, se definía como liberal y el segundo era afecto al régimen) coincidieron en identificar al emperador con el absolutismo y el final de la Antigüedad clásica. El decadentismo era abiertamente rechazado en un período en el que el régimen español (que se definió desde 1966 como «democracia orgánica») y Constantino dejó de ser presentado como un gobernante ejemplar. Por otra parte, tanto Gil como Suárez tendían a observar con escepticismo la sinceridad de la conversión del emperador, destacando, ante todo, su condición de político y administrador. Como se puede observar, de modo voluntario o no, las distintas imágenes de Constantino en la historiografía española durante el franquismo reflejan la propia evolución del régimen, y con él, de los cambios culturales y económicos que se produjeron desde el final de la Guerra Civil hasta la Transición. 